\title{
Comparison of Capacity Retention Rates During Cycling of Quinone-Bromide Flow Batteries
}

\section{Citation}

Gerhardt, Michael R., Eugene S. Beh, Liuchuan Tong, Roy G. Gordon, and Michael J. Aziz. 2016. Comparison of Capacity Retention Rates During Cycling of Quinone-Bromide Flow Batteries. MRS Advances: 1-8. doi:10.1557/adv.2016.667.

\section{Published Version}

doi:10.1557/adv.2016.667

\section{Permanent link}

http://nrs.harvard.edu/urn-3:HUL.InstRepos:29995338

\section{Terms of Use}

This article was downloaded from Harvard University's DASH repository, and is made available under the terms and conditions applicable to Open Access Policy Articles, as set forth at http:// nrs.harvard.edu/urn-3:HUL.InstRepos:dash.current.terms-of-use\#OAP

\section{Share Your Story}

The Harvard community has made this article openly available.

Please share how this access benefits you. Submit a story.

\section{Accessibility}




\title{
Comparison of Capacity Retention Rates During Cycling of Quinone-Bromide Flow Batteries
}

Michael R. Gerhardt ${ }^{1}$, Eugene S. Beh ${ }^{1,2}$, Liuchuan Tong ${ }^{2}$, Roy G. Gordon ${ }^{1,2}$, and Michael J. Aziz ${ }^{1}$

${ }^{1}$ Harvard John A. Paulson School of Engineering and Applied Sciences, Cambridge, MA 02138, U.S.A.

${ }^{2}$ Department of Chemistry and Chemical Biology, Harvard University, Cambridge, MA 02138, U.S.A.

\begin{abstract}
We use cyclic charge-discharge experiments to evaluate the capacity retention rates of two quinone-bromide flow batteries (QBFBs). These aqueous QBFBs use a negative electrolyte containing either anthraquinone-2,7-disulfonic acid (AQDS) or anthraquinone-2-sulfonic acid (AQS) dissolved in sulfuric acid, and a positive electrolyte containing bromine and hydrobromic acid. We find that the AQS cell exhibits a significantly lower capacity retention rate than the AQDS cell. The observed AQS capacity fade is corroborated by NMR evidence that suggests the formation of hydroxylated products in the electrolyte in place of AQS. We further cycle the AQDS cell and observe a capacity fade rate extrapolating to $30 \%$ loss of active species after 5000 cycles. After about 180 cycles, bromine crossover leads to sufficient electrolyte imbalance to accelerate the capacity fade rate, indicating that the actual realization of long cycle life will require bromine rebalancing or a membrane less permeable than Nafion ${ }^{\circledR}$ to molecular bromine.
\end{abstract}

\section{INTRODUCTION}

Cost effective grid scale energy storage would enable large-scale decarbonization of our electric grid. Redox flow batteries (RFBs) are a potentially low-cost solution to the intermittency problem faced by renewable energy sources such as wind and solar, but their viability requires long cycle life as well as long calendar life [1].

Recently, quinones have been demonstrated as inexpensive electroactive species for aqueous flow batteries [2-5]. One hundred charge-discharge cycles have been demonstrated in an all-quinone flow battery using a tiron posolyte (positive electrolyte) and an anthraquinone-2,6disulfonic acid negolyte (negative electrolyte), at 35\% depth of discharge, with no mention of capacity retention [5]. Our group demonstrated 750 deep cycles of a quinone-bromide flow battery (QBFB) using anthraquinone-2,7-disulfonic acid (AQDS), with 99.84\% capacity retention per cycle [6]. The AQDS-bromine battery voltage could be increased by using anthraquinone-2-sulfonic acid (AQS) as the negative electrolyte in place of AQDS, because AQS has a lower reduction potential than AQDS. In this work, we examine the long term stability of AQS and AQDS electrolytes in QBFBs through full-cell cycling and chemical analysis. Additionally, we surpass our previous capacity retention rate metric and achieve the highest capacity retention rate reported to date for a quinone-bromide flow battery, extrapolating to $30 \%$ loss of active species after 5000 operating cycles. 


\section{EXPERIMENT}

All electrochemical experiments were performed with a Gamry Reference 3000 potentiostat. Full-cell cycling experiments were performed with an additional Gamry Reference 30k booster. The flow cell, including a Nafion ${ }^{\circledR} 212$ membrane, is described in Ref [7]. AQDS and AQS electrolytes were prepared via an ion exchange process [2] to yield the acid form.

\section{AQDS and AQS cycling}

The cycling performance of AQS and AQDS cells was compared by constant current charge/discharge cycles at two different current densities. The cell was assembled with $25 \mathrm{~mL}$ of $1 \mathrm{M}$ AQDS, $1 \mathrm{M} \mathrm{H}_{2} \mathrm{SO}_{4}$ negolyte and $100 \mathrm{~mL}$ of $3 \mathrm{M} \mathrm{HBr}, 0.5 \mathrm{M} \mathrm{Br}_{2}$, and $0.5 \mathrm{M} \mathrm{H}_{2} \mathrm{SO}_{4}$ posolyte. $\mathrm{H}_{2} \mathrm{SO}_{4}$ was added to the posolyte to improve the osmotic balance between the two electrolytes. The cell was cycled 30 times at $0.25 \mathrm{~A} / \mathrm{cm}^{2}, 10$ times at $0.1 \mathrm{~A} / \mathrm{cm}^{2}$, and 50 additional times at $0.25 \mathrm{~A} / \mathrm{cm}^{2}$, with voltage cutoffs at $1.3 \mathrm{~V}$ and $0.3 \mathrm{~V}$. Without disassembling the cell, the AQDS negolyte was replaced with an AQS negolyte (1 M, in $2 \mathrm{M} \mathrm{H}_{2} \mathrm{SO}_{4}$ to keep the total proton concentration at $3 \mathrm{M}$ ), and the posolyte was replaced with a freshly prepared solution of $3 \mathrm{M} \mathrm{HBr}, 0.5 \mathrm{M} \mathrm{Br}_{2}$, and $0.5 \mathrm{M} \mathrm{H}_{2} \mathrm{SO}_{4}$. Following the same set of 90 cycles, the AQS electrolyte was replaced with fresh AQDS electrolyte, and the posolyte replaced as before.

\section{Evaluation of quinone crossover via cyclic voltammetry}

To evaluate quinone crossover via cyclic voltammetry, $2 \mathrm{~mL}$ samples of each posolyte solution were taken after the 90 -cycle experiment. Each sample was heated at $70{ }^{\circ} \mathrm{C}$ overnight to evaporate bromine. Following heating, each sample was re-dissolved in $20 \mathrm{~mL}$ of $1 \mathrm{M} \mathrm{H}_{2} \mathrm{SO}_{4}$. Cyclic voltammograms were performed with a $3 \mathrm{~mm}$ diameter glassy carbon working electrode (polished with $50 \mathrm{~nm}$ alumina slurry); an $\mathrm{Ag} / \mathrm{AgCl}$ reference electrode (3 $\mathrm{M} \mathrm{NaCl}$ filling solution, BASi); and a Pt coil counter electrode.

\section{Chemical analysis of negolytes before and after cycling}

${ }^{1}$ H NMR spectra were recorded on Varian INOVA 500 spectrometers and are reported in parts per million (ppm). Each sample solution a - d consisted of a $20 \mu \mathrm{L}$ aliquot of a negolyte prepared as described above (see: AQDS and AQS cycling), first diluted to $20 \mathrm{~mL}$ with $1 \mathrm{M}$ $\mathrm{H}_{2} \mathrm{SO}_{4}$. Subsequently, a $10.0 \mu \mathrm{L}$ aliquot of each of these solutions was further diluted to $1.00 \mathrm{~mL}$ with the same stock solution of $10.0 \mathrm{mM}$ sodium methanesulfonate in deuterium oxide $\left(\mathrm{D}_{2} \mathrm{O}\right)$. The sodium methanesulfonate functions as an internal standard, allowing the relative amounts of each substance to be quantified. Samples $a$ and $b$ were produced from the first AQDS negolyte before and after the 90 cycle experiment respectively. Samples c and d were produced from the AQS negolyte before and after the 90 cycle experiment respectively. In order to correct for the different NMR sensitivity of each proton, a very long relaxation time $(d 1=10.0 \mathrm{~s})$ was utilized.

High-resolution LC-MS analyses of the cycled AQDS and AQS negolytes were performed in the Small Molecule Mass Spectrometry Facility at Harvard University using Agilent ESI-TOF with HPLC.

\section{High capacity retention and posolyte-limit experiments}

The cell was assembled as described above, with the exception of the use of custom-built pyro-sealed interdigitated flow plates from Entegris. The flow plates are identical to the previous plates, with the exception of the milled surfaces of the channels being sealed in the Entegris plates. The sealing of the flow channels prevents seepage of fluid into the pores in the graphite. 
The negolyte was $20 \mathrm{~mL}$ of $1 \mathrm{M}$ AQDS in $1 \mathrm{M} \mathrm{H}_{2} \mathrm{SO}_{4}$, and the posolyte was $120 \mathrm{~mL}$ of $0.5 \mathrm{M}$ $\mathrm{Br}_{2}$ in $3 \mathrm{M} \mathrm{HBr}$. The cell was cycled at $0.25 \mathrm{~A} / \mathrm{cm}^{2}$ with voltage cutoffs of $1.3 \mathrm{~V}$ and $0.3 \mathrm{~V}$.

\section{RESULTS AND DISCUSSION}

\section{Capacity retention in AQDS-Br and AQS-Br cells}

As can be seen in Figure 1, the capacity of the AQS cell drops more rapidly than that of the AQDS cell. The capacity retention rate is also dependent on cycling time, which suggests a time-dependent loss mechanism causing more loss over the longer $0.1 \mathrm{~A} / \mathrm{cm}^{2}$ cycles. Due to a large excess of bromine and hydrobromic acid, the negolyte in these cells is the capacity-limiting electrolyte. For these cells, we suspect that the mechanisms causing capacity loss are dilution of the negolyte, negolyte leakage, negolyte crossover, and negolyte decomposition [3].
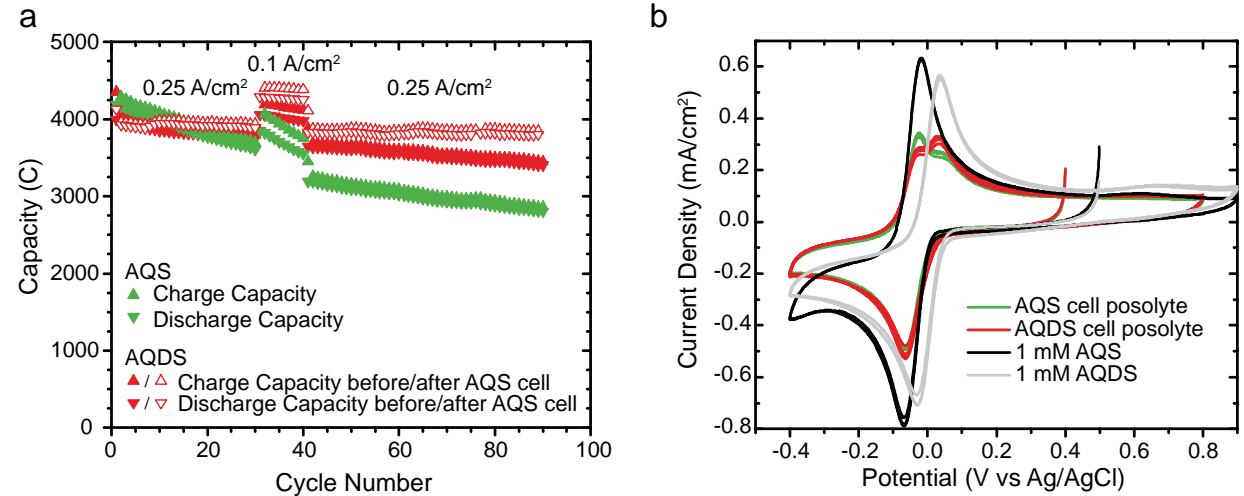

Figure 1. a. Charge and discharge capacities for AQS-bromide and AQDS-bromide cells. All three experiments were performed successively with the same cell build, by flushing the cell and replacing the electrolytes. First, an AQDS negolyte was cycled against a $\mathrm{Br}_{2} / \mathrm{HBr}$ posolyte (solid red triangles). Second, an AQS negolyte was cycled against a fresh posolyte (solid green triangles). Third, a fresh AQDS negolyte was cycled against a third fresh posolyte (open red triangles). b. Cyclic voltammograms of the posolyte from the AQS-Br cell (green) and the second AQDS-Br cell (red); in each case, the posolyte was first heated to evaporate $\mathrm{Br}_{2}$. For comparison, we show pristine $1 \mathrm{mM}$ AQS (gray) and $1 \mathrm{mM}$ AQDS (black) in $1 \mathrm{M} \mathrm{H}_{2} \mathrm{SO}_{4}$.

Table 1. Volume of the negolyte during cycling for each of the three cell cycling runs.

\begin{tabular}{l|lll} 
& First AQDS & AQS & Second AQDS \\
\hline Volume Gain (mL) & $8 \pm 1$ & $12 \pm 1$ & $13 \pm 1$ \\
Final Volume (mL) & $33 \pm 1$ & $37 \pm 1$ & $38 \pm 1$
\end{tabular}

Dilution of the negolyte, typically caused by osmotic imbalance between the negolyte and posolyte, has an indirect effect on the cell capacity as it can increase the mass transport overpotential, causing the cell to reach the voltage limits sooner than expected. Negolyte dilution was observed during cycling by using a graduated cylinder as the negolyte reservoir. The volume gain was approximately the same for the AQS and AQDS cell runs over time, as shown in Table 1 , indicating that negolyte dilution cannot explain the observed difference in capacity retention between AQS and AQDS cells. The volume measurements also rule out negolyte leakage as a potential explanation for the capacity retention difference. 


\section{Crossover of AQDS and AQS}

To further investigate the crossover rates of the quinones, the cycled electrolytes were analyzed via cyclic voltammetry (Figure 1b) to quantify the posolyte quinone contents in each case. The bulk concentration of an electroactive species can be estimated from the peak current density of a cyclic voltammogram if the diffusivity and number of electrons transferred $n$ are known [8]. The diffusivity of AQDS was measured [2] to be $3.8(1) \times 10^{-6} \mathrm{~cm}^{2} / \mathrm{s}$, whereas for AQS [4] it is $3.71 \times 10^{-6} \mathrm{~cm}^{2} / \mathrm{s}$. Assuming $n=2$, with the scan rate $v$ set to $100 \mathrm{mV} / \mathrm{s}$, the reduction peak of quinones suggests a concentration of $7 \mathrm{mM}$ quinone in the posolyte in each case, indicating approximately $135 \mathrm{C}(\sim 3.5 \%)$ of lost capacity. This measured quinone crossover is equivalent to a capacity loss current of $0.04 \mathrm{~mA} / \mathrm{cm}^{2}$. The similarity in the reduction peak height between each sample indicates approximately equal concentrations of AQDS and AQS that have crossed over to each posolyte. Therefore, we cannot ascribe the reduced capacity retention in AQS cells to crossover.

\section{Possible decomposition of AQS}
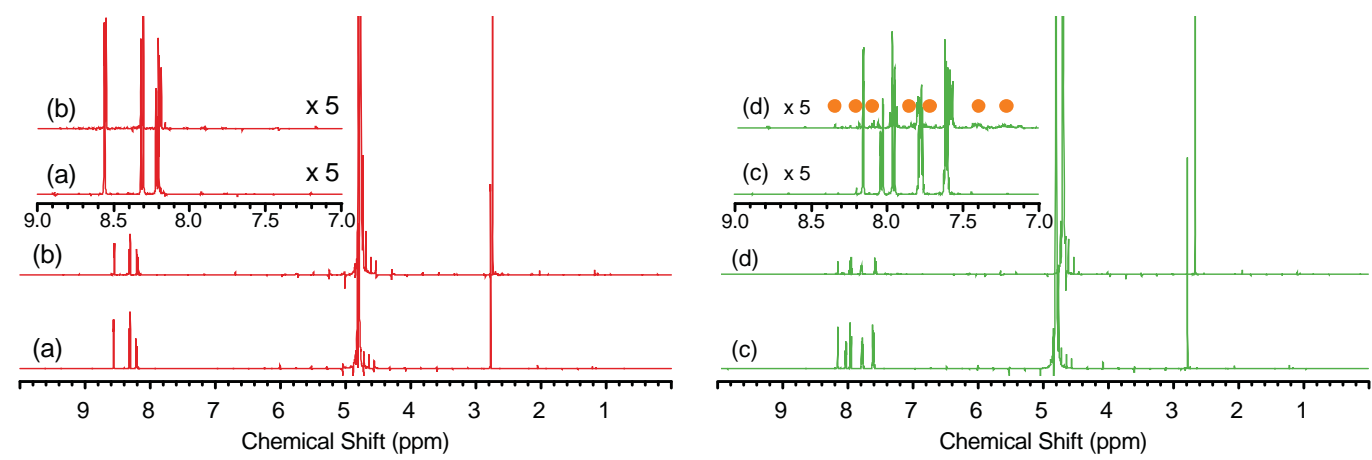

Figure 2. a-b. ${ }^{1} \mathrm{H}$ NMR spectra of AQDS before (a) and after (b) cycling against aqueous $\mathrm{HBr} / \mathrm{Br}_{2} / \mathrm{H}_{2} \mathrm{SO}_{4}$ for 90 cycles. c-d. NMR spectra of AQS before (c) and after (d) cycling against aqueous $\mathrm{HBr} / \mathrm{Br}_{2} / \mathrm{H}_{2} \mathrm{SO}_{4}$ for 90 cycles. Peaks at $\sim 4.8 \mathrm{ppm}$ and $\sim 2.8 \mathrm{ppm}$ correspond to partially deuterated water (HDO) and sodium methanesulfonate respectively, the latter of which was added as an internal integration standard. Spectra heights are normalized to the area under each peak at 2.8 ppm. Inset: Magnification (x5) of the 7.0 - 9.0 ppm region. Cycling of AQS is associated with the formation of other NMR-active organic compounds that appear further upfield compared to AQS (peaks marked); for AQDS no NMR-active decomposition products could be identified.

Each electrolyte was examined before and after cycling by NMR (Figure 2). In either case loss of the starting material could be observed as a decrease in peak area: for AQS, 33\% of the AQS peak area remained after cycling, whereas for AQDS, 58\% remained. After correcting for negolyte dilution (Table 1), these results indicate 52\% moles AQS remaining and 76\% moles AQDS remaining in their respective negolytes.

The appearance of new peaks in the AQS NMR spectrum indicates a decomposition product or products. From the upfield chemical shift of the AQS decomposition products, it appears that one or more aromatic protons on AQS is substituted with an electron-donating group, likely -OH. The integration for the decomposition products, however, does not account for all the AQS lost, so this material likely ends up decomposing further into either an insoluble product, or a product containing no $\mathrm{C}-\mathrm{H}$ bonds. High-resolution mass spectrometry on the cycled 
AQS negolyte revealed the existence of 2-hydroxy-9,10-anthraquinone $(\mathrm{m} / \mathrm{z}=272.0149 \pm$ 0.005), suggesting the replacement of a sulfonate with a hydroxy group during cycling, resulting in an insoluble compound.

Although the concentration of AQDS before and after cycling appears to have dropped, no decomposition products were detectable by NMR. One possibility is that AQDS decomposes into numerous different products, each of which is too small in quantity to detect. Alternatively, AQDS could decompose into an insoluble or NMR-inactive species, or a species that interacts with bromine to form an insoluble or NMR-inactive species. High-resolution mass spectrometry on the cycled negolyte revealed three additional compounds, with masses suggesting (1) the replacement of one sulfonate with a hydroxy group $(\mathrm{m} / \mathrm{z}=302.9963 \pm 0.005),(2)$ the replacement of both sulfonates with hydroxy $(\mathrm{m} / \mathrm{z}=239.0344 \pm 0.005)$, and (3) the addition of a hydroxy without replacing a sulfonate $(\mathrm{m} / \mathrm{z}=382.9532 \pm 0.005)$. Compounds (1) and (3) are likely to remain soluble and electrochemically active, so their formation may not result in capacity fade.

Both AQDS and AQS in their oxidized forms appear to be stable, even in boiling $\mathrm{Br}_{2}$ and $\mathrm{HBr}[2,7]$. Hence we believe these reactions to start with the reduced forms of AQDS and AQS.

\section{Extending AQDS-Br cycle life \& impact of bromine crossover on cycle life}
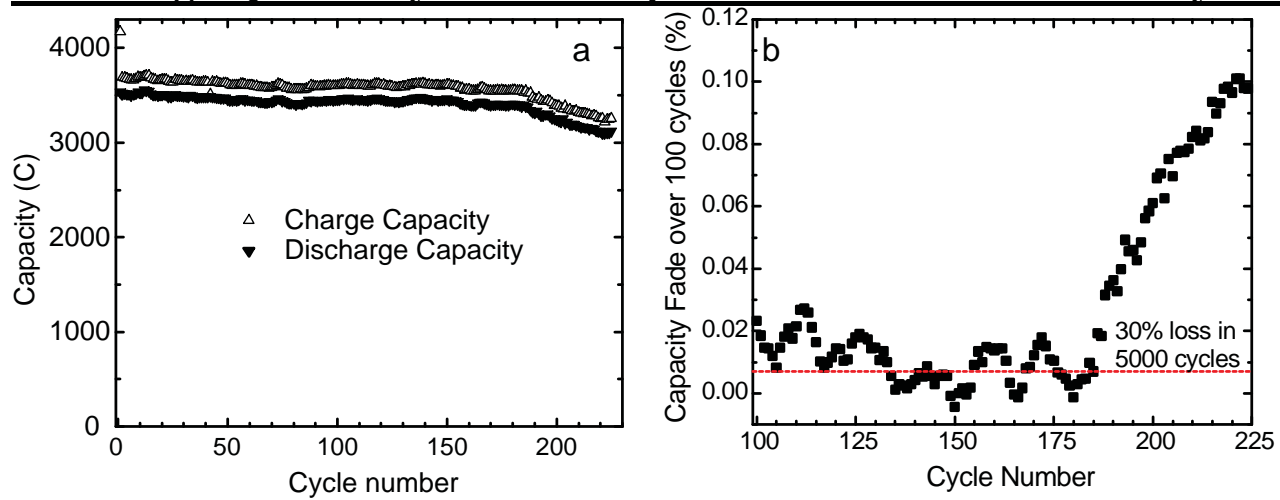

Figure 3. a. Charge and discharge capacities and b. capacity fade over prior 100 cycles as a function of cycle number in an AQDS-bromide cell.

To further examine the long-term stability of AQDS, an AQDS-bromide cell was constructed and cycled at $0.25 \mathrm{~A} / \mathrm{cm}^{2}$ for over 200 cycles. The cell shows excellent capacity retention initially, before a rapid drop in capacity near cycle 183, as shown in Figure 3a. Figure $3 \mathrm{~b}$ reports the capacity fade per 100 cycles, for each set of continuous 100 cycles in the 225 cycle experiment. The red line represents the fade rate $(0.00713 \%$ per cycle $)$ that extrapolates to $70 \%$ remaining capacity after 5000 cycles. Thus, after an initial conditioning period, the cell is able to cycle with this capacity fade rate - with some noise - until the sudden increase in capacity fade. Converted to a capacity loss current $\left(0.03 \mathrm{~mA} / \mathrm{cm}^{2}\right)$, this low capacity fade rate is approximately equivalent to our measurements of quinone crossover rates (see: Crossover of AQDS and AQS), indicating that this capacity loss is likely due to AQDS crossover.

We attribute the sudden increase in cycle fade at cycle 183 to a change in the capacitylimiting electrolyte of the cell. The current efficiency averaged 95.7\%. Thus, the state of charge of the posolyte gradually increases as the cell is cycled, because $4.3 \%$ of the bromine produced during each charge cycle is not converted back to bromide. Once there is insufficient bromide, bromide in the posolyte becomes the capacity-limiting reagent in the cell upon charging, at 
which point the capacity begins its rapid decline [3]. Converted to a capacity loss current, this new fade rate $\left(0.23 \mathrm{~mA} / \mathrm{cm}^{2}\right)$ is less than what would be predicted by bromine crossover alone $\left(1.2 \mathrm{~mA} / \mathrm{cm}^{2}\right)$ [3]. This discrepancy could be due to variation in bromine crossover rate with posolyte state of charge[9].

\section{CONCLUSIONS}

The AQS-bromine cell exhibits a lower capacity retention rate than does the AQDSbromine cell. AQS appears to undergo a hydroxylation/decomposition reaction. With careful control of AQDS leakage from the cell by sealing the flow plate channels, an AQDS-bromide flow battery can be cycled hundreds of times with high capacity retention. The extrapolation to $30 \%$ capacity loss in 5000 cycles is interrupted by the onset of a sudden capacity fade mechanism which we interpret as the posolyte becoming the capacity-limiting side. This result indicates that AQDS will survive 5000 reductions and 5000 oxidations without unacceptable amounts of molecule destruction, assuming sufficient posolyte supply.

Presently, loss of bromine from the posolyte limits the lifetime of the AQDS-bromide flow battery. The development of bromine rebalancing methods, bromine complexing agents, or membranes impermeable to bromine appears to be critical for long-term operation of aqueoussoluble organic flow batteries containing bromine.

\section{ACKNOWLEDGMENTS}

This work was partially funded through the US Department of Energy ARPA-E Award \#DE-AR0000348 and partially funded through the Harvard John A. Paulson School of Engineering and Applied Sciences. This work was also supported by funding from the Massachusetts Clean Energy Technology Center. We acknowledge Sergio Granados-Focil, Marc-Antoni Goulet, David Kwabi, and Andrew Wong for helpful discussions and a critical reading of the manuscript.

\section{REFERENCES}

1. G. L. Soloveichik, Chem. Rev. 115 (20), 11533-11558 (2015).

2. B. Huskinson, M. P. Marshak, C. Suh, S. Er, M. R. Gerhardt, C. J. Galvin, X. Chen, A. Aspuru-Guzik, R. G. Gordon and M. J. Aziz, Nature 505 (7482), 195-198 (2014).

3. Q. Chen, L. Eisenach and M. J. Aziz, J. Electrochem. Soc. 163, A5057-A5063 (2016).

4. B. Yang, L. Hoober-Burkhardt, F. Wang, G. K. Surya Prakash and S. R. Narayanan, J. Electrochem. Soc. 161, A1371-A1380 (2014).

5. B. Yang, L. Hoober-Burkhardt, S. Krishnamoorthy, A. Murali, G. K. S. Prakash and S. R. Narayanan, J. Electrochem. Soc. 163 (7), A1442-A1449 (2016).

6. B. Huskinson, M. P. Marshak, M. R. Gerhardt and M. J. Aziz, ECS Trans. 61, 27-30 (2014).

7. M. R. Gerhardt, L. Tong, R. Gomez-Bombarelli, Q. Chen, M. P. Marshak, C. J. Galvin, A. Aspuru-Guzik, R. G. Gordon and M. J. Aziz, Adv. Energy Mat. (in press) (2016). Available: http://aziz.seas.harvard.edu/files/azizgroup/files/mja264-manuscript.pdf

8. A. J. Bard and L. R. Faulkner, Electrochemical methods : fundamentals and applications. (Wiley, New York, 2001).

9. K. T. Cho, M. C. Tucker, M. Ding, P. Ridgway, V. S. Battaglia, V. Srinivasan and A. Z. Weber, ChemPlusChem 80 (2), 402-411 (2015). 
Copyright WILEY-VCH Verlag GmbH \& Co. KGaA, 69469 Weinheim, Germany, 2013.

\section{Supporting Information}

\section{Anthraquinone Derivatives in Aqueous Flow Batteries}

Michael R. Gerhardt, Liuchuan Tong, Rafael Gómez-Bombarelli, Qing Chen, Michael P. Marshak, Cooper J. Galvin, Alán Aspuru-Guzik, Roy G. Gordon, and Michael J. Aziz *

\section{Supplemental Methods}

\subsection{Ion exchange}

A glass ion exchange column was filled with Amberlyst ${ }^{\circledR} 15(\mathrm{H})$ ion exchange resin (Alfa Aesar). A 1 M hydrochloric acid solution was prepared concentrated stock (37\%, Sigma Aldrich) diluted with deionized water (18.2 M $\Omega$, Millipore). This hydrochloric acid solution was used to activate the column prior to passing an anthraquinone solution through the column. After passing through the column, the ion-exchanged anthraquinone solution was evaporated to dryness on a hot plate at approximately $100{ }^{\circ} \mathrm{C}$ and redissolved in deionized water. Solution was passed successively through medium and fine porosity glass frit filters to remove insoluble material.

\subsection{Synthesis of 1,8-dihydroxyanthraquinone-2,7-disulfonic acid}

Fuming sulfuric acid (68 ml, $20 \% \mathrm{SO}_{3}$ content, Alfa Aesar) was added to 1,8-

dihydroxyanthraquinone (40 g, $165.3 \mathrm{mmol}, \mathrm{TCI})$ in an oven-dried round-bottom flask, and the flask was covered with a watch glass. The mixture was heated to $180{ }^{\circ} \mathrm{C}$ overnight while stirring. After cooling to room temperature, the reaction mixture was poured into cold water $(200 \mathrm{ml})$ and $\mathrm{NaCl}$ brine $(100 \mathrm{~mL})$ was added. A brown precipitate formed, which was filtered, washed with brine $(3 \times 100 \mathrm{~mL})$ and rapidly washed with cold water $(50 \mathrm{~mL})$. The resulting precipitate was vacuum dried without further purification to provide $70 \mathrm{~g}(95 \%$ 
yield) of 1,8-dihydroxyanthraquinone-2,7-disulfonate disodium salt. The protonated form was obtained by the ion exchange procedure defined above.

1.3 Synthesis of 1,4-dihydroxyanthraquinone-2,3-dimethylsulfonic acid: Sodium sulfite $(2.96 \mathrm{~g}, 23.5 \mathrm{mmol})$ and potassium iodide $(195 \mathrm{mg}, 1.17 \mathrm{mmol})$ were added to a solution of 1,4-dihydroxy-2,3-bis(bromomethyl)anthraquinone $(5 \mathrm{~g}, 11.74 \mathrm{mmol}$, prepared according to Ref. $\left.{ }^{[22]}\right)$ in water/acetonitrile $(100 \mathrm{~mL}, 5: 1 \mathrm{v} / \mathrm{v})$. The mixture was refluxed under nitrogen atmosphere for 18 hours, and cooled to room temperature. The mixture was then passed through an ion exchange column filled with Amberlyst ${ }^{\circledR}$ 15(H) ion exchange resin (Alfa Aesar) activated with $1 \mathrm{M}$ hydrochloric acid. The resulting solution was concentrated by vacuum drying to produce $3.3 \mathrm{~g}$ (66\% yield) of 1,4-dihydroxy-anthraquinone-2,3-

dimethylsulfonic acid. ${ }^{[22]} \mathrm{HRMS}$ (ESI) m/z: calcd for $\mathrm{C}_{16} \mathrm{H}_{11} \mathrm{O}_{10} \mathrm{~S}_{2},[\mathrm{M}-\mathrm{H}]^{-}, 426.9799$; found, 426.9803 .

\subsection{Proton nuclear magnetic resonance}

${ }^{1} \mathrm{H}$ NMR spectra were recorded using Varian INOVA $500(500 \mathrm{MHz}) \mathrm{NMR}$ spectrometers at $23{ }^{\circ} \mathrm{C}$. Proton chemical shifts are expressed in parts per million (ppm, $\delta$ scale) and are referenced to residual ${ }^{1} \mathrm{H}$ in the NMR solvent $\left(\mathrm{CDCl}_{3}, \delta 7.26 \mathrm{ppm} ;\left(\mathrm{CD}_{3}\right)_{2} \mathrm{SO}\right.$, $2.50 \mathrm{ppm})$

\subsection{Electrolyte conductivity measurements}

Electrolyte conductivity measurements were performed using a custom-built conductivity cell comprising a length of $1 / 4$ inch wide PFA tubing, approximately $8.5 \mathrm{~cm}$ long with a 1/8 inch inner diameter, two T-shaped PVDF push-to-connect fittings, and two $1 / 4$ inch diameter niobium rods for electrodes. Galvanostatic electrochemical impedance spectroscopy (EIS) was performed using a Gamry Reference 3000 potentiostat, sweeping from $1 \mathrm{MHz}$ to $100 \mathrm{~Hz}$ with $0.01 \mathrm{~A}$ rms applied AC current. The conductivity cell was calibrated with $1 \mathrm{M}$ and $0.1 \mathrm{M}$ potassium chloride solutions and found to have an L/A constant of $109 \pm 1 \mathrm{~cm}^{-1}$. ${ }^{25]}$ Impedances with a phase value between 2 and -2 degrees were averaged to calculate the 
solution resistance. Dividing the cell L/A constant by the resistance gives the electrolyte conductivity. Nyquist plots are shown in Figure S1.

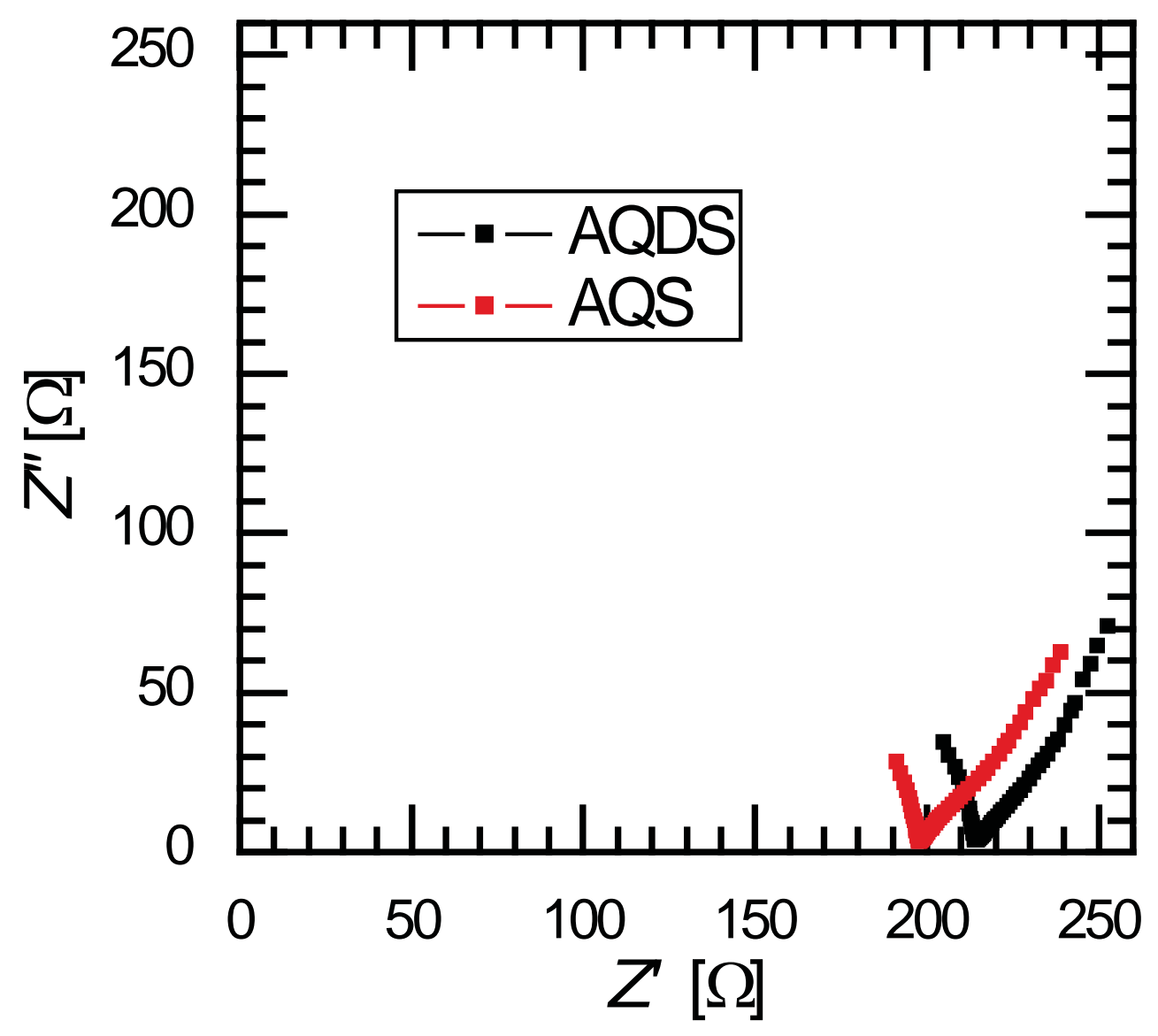

Figure S1. Nyquist plots for AQDS and AQS electrolytes (1 M quinone, $3 \mathrm{~m}$ total proton content, additional protons provided by sulfuric acid). Electrolyte conductivities were $0.51 \mathrm{~S}$ $\mathrm{cm}^{-1}$ for AQDS and $0.55 \mathrm{~S} \mathrm{~cm}^{-1}$ for AQS. 


\section{Quinone stability to electrochemical cycling - voltage profiles}

a.

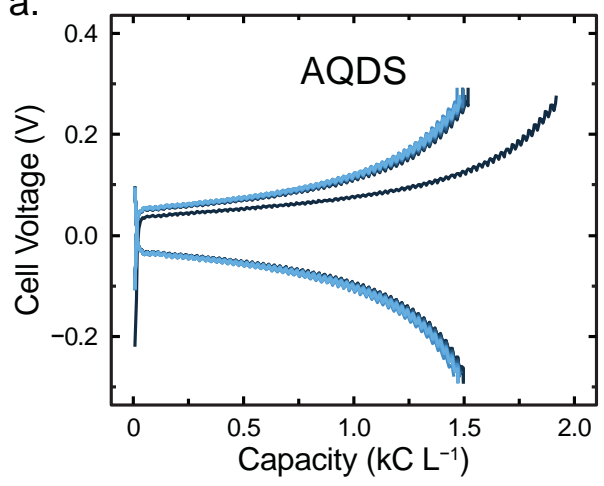

C.

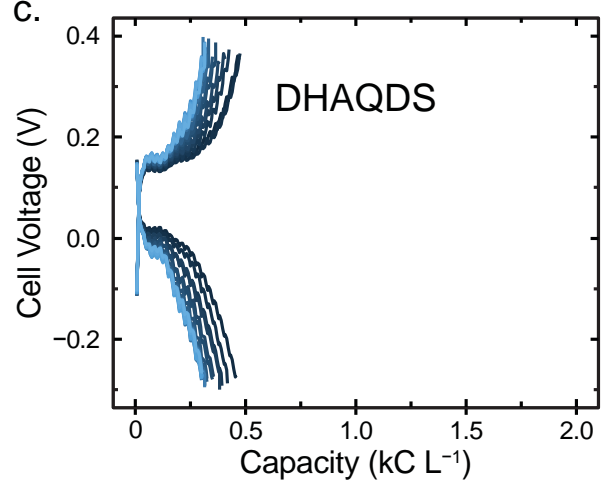

b.

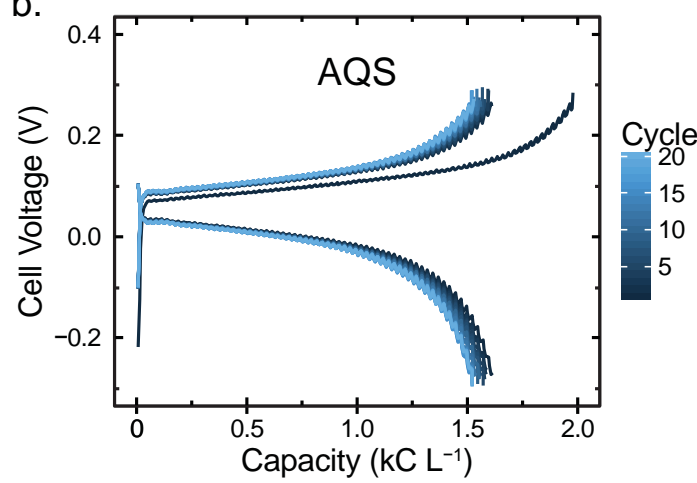

d.

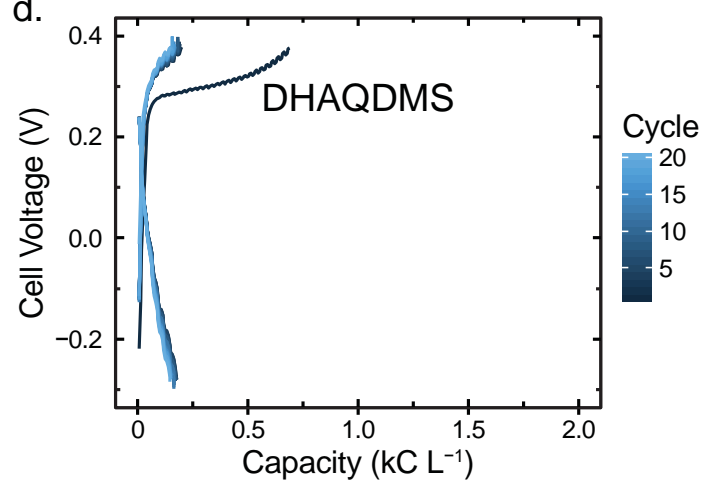

Figure S2. Voltage profiles for constant-current cycling experiments of each of the four molecules studied against an AQDS- $\mathrm{H}_{2}$ AQDS electrolyte. All cycling was performed at 50 $\mathrm{mA} \mathrm{cm}{ }^{-2}$. The voltage oscillations in the figures are a result of pulsating flow from the diaphragm pumps used to circulate the electrolyte. These oscillations are enhanced due to the low concentration $(0.01 \mathrm{M})$ of quinone, resulting in test cells which are extremely sensitive to mass transport conditions. The drop in capacity from cycle 1 to 2 in the AQDS and AQS cells can be explained by an inability to fully discharge the cell after the first full charge, due to these mass transport limitations. Constant voltage holds (figure S3) demonstrate little to no capacity fade after these 20 cycles. 
WILEY-VCH

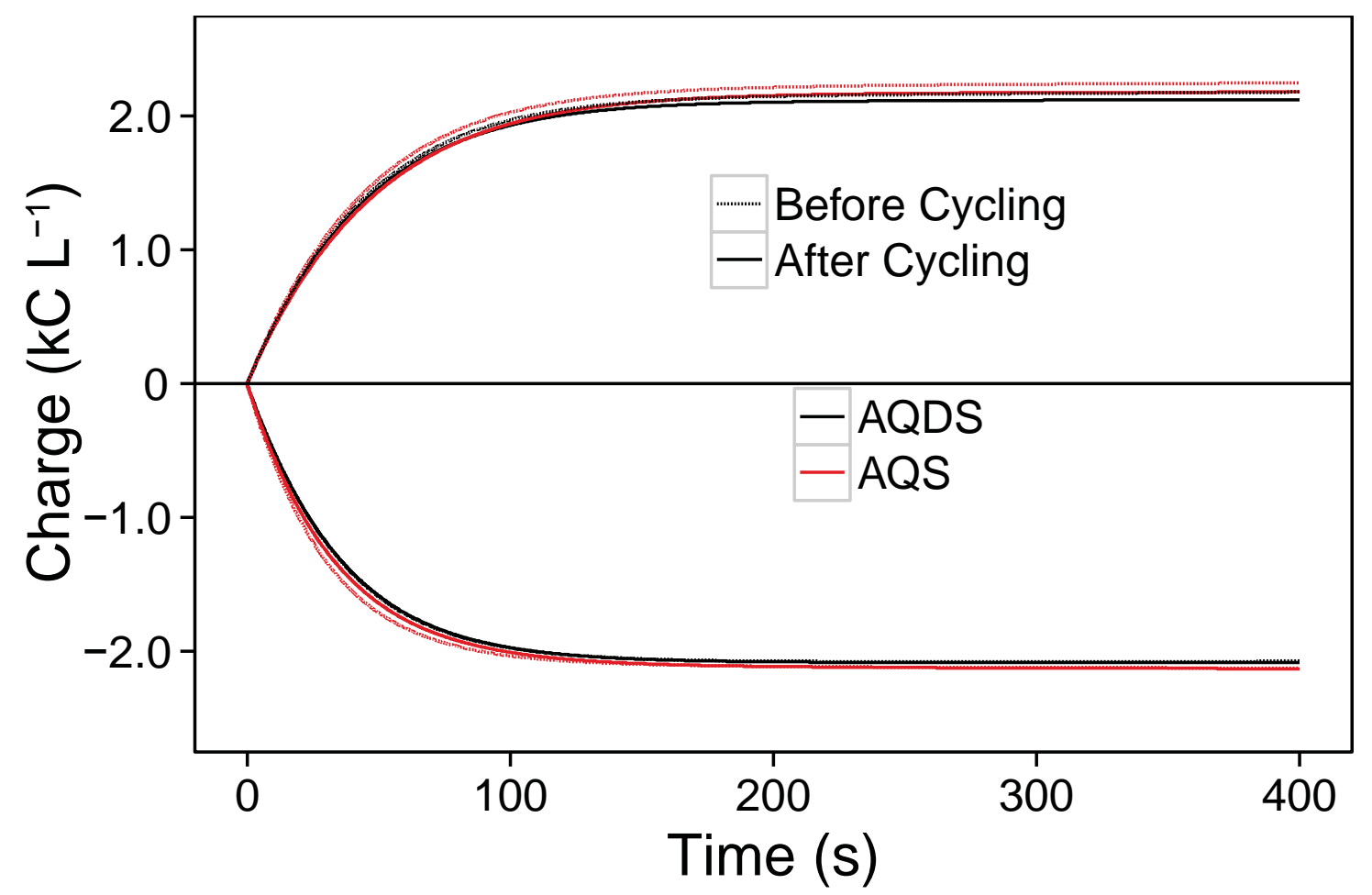

Figure S3. Constant voltage charging/discharging of AQDS and AQS low-concentration electrolytes immediately prior to or following the constant-current cycling shown in figures $4 \mathrm{a}$ and $\mathrm{S} 2$. The cell was charged at $0.3 \mathrm{~V}$ and discharged at $-0.3 \mathrm{~V}$. These results demonstrate little to no capacity fade in either cell, provided enough time is given for the cell to charge and discharge. 